\title{
Disaster Risk Management: Disciplinary status and prospects for a unifying theory
}

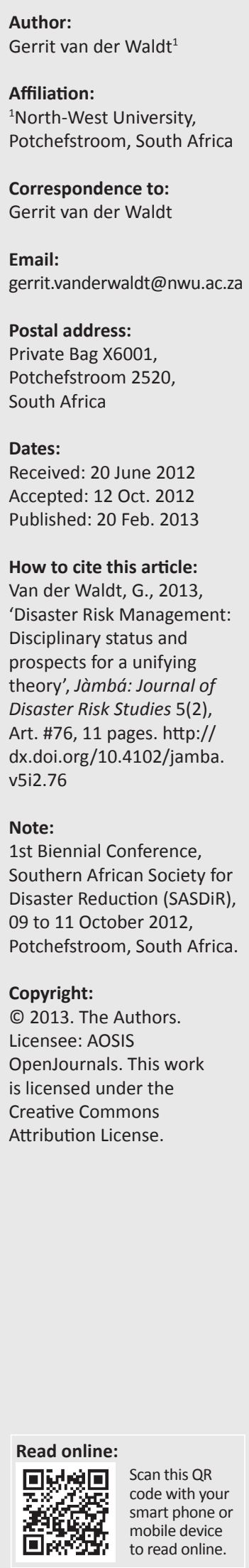

The purpose of this paper is to explore the disciplinary status of Disaster Risk Management (DRM) as an emerging, applied, social science and to consider prospects for the establishment of a unifying theory or philosophical underpinning for the discipline. The exploration of the disciplinary status is facilitated by content analyses of knowledge products of the discipline, including study material, research reports, and completed postgraduate research to determine the typical categories or specialist areas or domains (curricula) of the discipline as well as a subsequent content analysis of Jàmbá articles. The research findings are then plotted on a focus area maturity model to facilitate opinion formulation regarding the disciplinary status of DRM. The findings reveal surprisingly high levels of maturity and set the parameters for a continuous discourse regarding the current disciplinary status of DRM in South Africa. The paper further proposes steps to establish a unifying theory as overarching paradigm for theory development and testing.

\section{Introduction}

As an emerging discipline, Disaster Risk Management (DRM) is both an academic field of study and an applied field for the purposes of developing practitioners for careers in disaster-related professions. As in adjacent, applied disciplines, such as Public Administration and Development Studies, this usually creates tension between knowledge production and general research endeavours. Due to the immediate needs of practice (professional career demands) and the demographic as well as socio-political and economic challenges that South Africa faces, scholars in the field of DRM may be inclined to focus more attention on skills development at the expense of research and theory development. In this regard, Perry and Kraemer (1986:364) warn that if research is eclectic and skewed towards problem-solving, and is poorly supported, it cannot mature to a point where it is 'capable of sustaining the knowledge creation needs of the field'. A cumulative and unifying knowledge base in the field is thus necessary for the development of DRM into an established applied discipline.

The primary aim of this paper is to assess the current disciplinary status of DRM through content analyses as method and the utilisation of a focus area maturity model. The secondary aim of the paper is to contemplate prospects for a unifying theory for the field. It is argued that DRM needs to develop a unifying theory that could serve as an 'umbrella' paradigm for fundamental theories and approaches that would guide both the study and professional fields in their knowledge production efforts. For purposes of this paper, Disaster Risk 'Management' is preferred as the name of the study field.

Through content analysis as research method, this paper will analyse the content of journal papers, knowledge products, and postgraduate research in the field to ascertain its current disciplinary status. It should be noted that this analysis only pertains to DRM as practised at North-West University as case study, and that research findings cannot be generalised to DRM either in South Africa or internationally.

\section{The nature and characteristics of a discipline}

The philosophical roots of a discipline as an academic field or branch of knowledge could be sought from the classical philosophies of Socrates, Plato and Aristotle. In his work Gorgias, Plato wrote a Socratic dialogue (350BC) in which he maintains that only philosophers have the courage to face facts, and that their influence rests entirely upon their ability to present rational and logical deductions and empirical inductions based on observations (Benardete 1991:85). For Alexander (2011:195), scholars are actors who can exercise judgement because they are 'free-floating, independent of particular commitments'. Habermas also postulates that scholars should 'engage in unfettered critical discourse' (quoted in Alexander 2011:195). 
According to Pierce (1991:22) and Ziman (2000), there exists a long semantic history of disciplina as a term for the ordering of knowledge for the purposes of instruction. A 'discipline' is defined by the Oxford English Dictionary (available online, from http: / /oxforddictionaries.com) as 'a branch of learning or scholarly instruction'. A field of study, as defined by an academic discipline, provides a framework for any scholarly activity, and tertiary institutions are typically organised around clusters of similar disciplines.

Disciplines tend to characterise, classify, specialise, qualify and validate knowledge (Doheny, Cook \& Stopper 1987; Foucault 1979:223). Liles et al. (1995) concur and add that a discipline can be regarded as a method or way to view an occurrence or phenomenon. Disciplines develop a corpus of knowledge, developed and expanded through research that is distinct from that of other disciplines and provides a foundation for practice. Disciplines within the applied branches of science usually have a strong relationship with practice (Denning 1989; Keen 1980). Separate curricula, professional societies and journals advance professionalism and are necessary for a separate discipline (Maynard 1971).

Disciplines become recognised after significant existing researchers and practitioners become known in the field. Disciplines, according to Salvendy (1982), are usually defined by:

- the nature and focus of research undertaken by scholars in the field

- the content of learning programmes (curricula)

- the academic journals in which research in the field is published

- the nature and functioning of professional bodies and societies

- the departments or faculties to which its scholars belong.

Disciplines may be divided into subareas which have an underlying unity of subject matter, a substantial theoretical component, significant abstractions, and important design and implementation issues (Denning 1989).

Disciplines are based upon and build upon the works other disciplines referred to as 'reference' or 'adjacent' disciplines (Doheny et al. 1987), from which theories and methods are assessed, not merely adopted (Keen 1980:10). However, uniqueness or distinction from other disciplines is imperative to recognition (Denning 1989; Keen 1980:11; Snodgrass 1987). A discipline should also be identifiable and should sustain its own literature (Denning 1989; Snodgrass 1987).

For scholars, such knowledge structuring and the systematic organisation of disparate fields of inquiry are essential processes in an effort to acquire a comprehensive view of study field-related issues. So-called 'mature' sciences have well-developed paradigms and have unambiguous ways of defining, ordering, and investigating knowledge (Abbott 2001; Augsburg 2005). Numerous analytical frameworksareevidentintheliteratureforclassifyingacademic disciplines for the purposes of comparative study (Becher 1987;
Biglan 1973:195-203). Four of these frameworks have drawn much of the focus of empirical work in the study of discipline differences:

- Codification: refers to the condition whereby knowledge can be consolidated, or codified, into succinct and interdependent theoretical formulations.

- Paradigm development: refers to the extent to which a discipline possesses a clearly defined 'academic law' or ordering of knowledge and associated social structures.

- Consensus: refers to the degree of consensus about theory, methods, techniques, and problems. Consensus implies unity of mind on elements of social structure and the practice of science. Researchers commonly attribute high levels of consensus to the physical sciences, low levels to the social sciences, and even lower levels to the humanities.

- The Biglan Model: Anthony Biglan developed his taxonomy of academic disciplines which comprises three dimensions: (1) the degree to which a paradigm exists (paradigmatic or pre-paradigmatic, alternatively referred to as hard versus soft disciplines); (2) the extent to which the subject matter is practically applied (pure versus applied); and (3) involvement with living or organic matter (life versus non-life systems). Social sciences and humanities are regarded as sciences with less-developed paradigms and low consensus on knowledge bases and modes of inquiry (Biglan 1973:199).

According to Liles et al. (1995), a discipline consists of six characteristics, each of which is briefly addressed below. These are utilised towards the end of the paper as 'focus areas' within a maturity model to consider the disciplinary status of DRM. See Table 1 below.

- Focus of study: The focus of a discipline refers to what is studied. A discipline has objectives, a corpus of knowledge and research protocols which direct its study focus (Doheny et al. 1987; Snodgrass 1987).

- World view or paradigm: As a new scientific discipline emerges, various interpretations and theories compete. This process continues until a comprehensive viewpoint becomes accepted by scholars. Kuhn (1970) calls this viewpoint a paradigm or world view. This world view or paradigm determines the framework necessary for the development of the discipline through practice and research (Doheny et al. 1987). 'Mature' sciences with well-developed paradigms are thought to have clear and unambiguous ways of defining, ordering, and investigating knowledge. At the opposite end of the scale are fields such as education and sociology, which are described as pre-paradigmatic. These fields

TABLE 1: Characteristics of a discipline.

\begin{tabular}{ll}
\hline Number & Characteristics \\
\hline 1 & Focus of study \\
2 & Paradigm or world view \\
3 & Reference or adjacent disciplines \\
4 & Principles and practices \\
5 & Active research agenda \\
6 & Education and professionalism \\
\hline
\end{tabular}

Source: Adapted from Liles et al. (1995) 
are characterised by a high level of disagreement as to what constitutes new knowledge, what are appropriate methods for inquiry, what criteria are applied to determine acceptable findings, what theories are proven, and the importance of problems to study.

- Reference disciplines: Disciplines usually emerge from the need to solve new problems that are not presently addressed by existing disciplines. Reference or adjacent disciplines' bodies of knowledge facilitate the establishment of an emerging discipline (Keen 1980). To develop a recognised discipline, researchers must discover the contributions of supporting disciplines. New disciplines build on the knowledge, subject matter, methods, tools, and theories of existing disciplines in order to solve these new problems (Liles et al. 1995).

- Principles and practices: Principles and practices are the foundation or essence of a discipline, and promote ordered study. They incorporate the paradigm, methodologies, models and procedures necessary for the advancement of the discipline through research and theory development (Liles et al. 1995).

- Active research or theory development agenda: An active research agenda encompasses the fundamental questions that the discipline generates and studies. An active research agenda is characterised by the continuallyexpanding research and the fact that the research agenda is complex and substantial enough to be divided into subdomains. Particularly in applied sciences, practitioners uncover new problems and communicate those problems to researchers, who in turn suggest solutions through existing research agendas or through new research and communicate them to the aforementioned practitioners. This is an iterative cycle that facilitates the enhancement of both theory and practice (Liles et al. 1995).

- Deployment of education and promotion of professionalism: Mechanisms of deployment include refereed professional journals, professional societies and conferences, and curricula in universities. Liles et al. (1995) state that developing and maintaining these mechanisms of deployment results in the recognition of a new discipline. Over time, a written record of knowledge will accumulate and will thus represent a historical account of thought progression.

It should be noted that although the characteristics highlighted above provide an indication of the nature of a discipline, there exist no formal criteria for the development of an academic discipline (Pierce 1991:22). Fields of study usually have several subdisciplines, or branches, and the distinguishing lines between these are often both arbitrary and ambiguous (Abbott 2001; Pierce 1991:23).

\section{Disaster risk management as an emerging, applied discipline}

The relative recency of the emergence of DRM as a discipline is confirmed by Wisner, Gaillard and Kelman (2012:xxviii) who state that Disaster Risk Reduction (DRR) only came about as recently as the 1990s, when experts and practitioners became involved in the United Nations International Decade for Natural Disaster Reduction. Towards the end of the decade, in 1999, very few governments had any kind of policies or programmes in place to reduce risk and vulnerability to hazards.

Van Niekerk, Mokonyama and Reid (2002:59) explored the historical roots of Disaster Management in South Africa and further confirm the recency of the emergence of DRM by stating that until June 1994, South Africa did not have a holistic approach to deal with disasters. Elements of disaster management, which are now mainstreamed in DRM, could, however, be traced back to the establishment of civil defence organisations after the Second World War. In 1957 the Civil Defence was established, followed by the creation of a Council for Civil Defence Services in 1959 (Van Niekerk et al. 2002:60). The main impetus to develop a more holistic, comprehensive approach in South Africa, however, only came about as a result of the United Nations International Decade for Natural Disaster Reduction (1990-1999), as confirmed by Wisner et al. (2012:xxviii), and due to the devastating floods in the Cape in June 1994. These events resulted in the establishment of an Inter-Ministerial Committee for Disaster Management (IMC) in 1997, the publication of the Green Paper on Disaster Management (1998), the White Paper on Disaster Management (1999) and, eventually, the promulgation of the Disaster Management Act (Act 57 of 2002). For the first time, South Africa had an effective, holistic approach to disaster management, linked to developmental initiatives. The stimuli provided by a comprehensive legislative framework and the establishment of mechanisms in terms of the Disaster Management Act, such as the National Disaster Management Framework, the National Disaster Management Advisory Forum, the Intergovernmental Committee on Disaster Management, and the establishment of the National Disaster Management Centre, have led to significant interest in the field from both practitioners and scholars from established disciplines such as Public Administration and Management, and Development Studies.

Compared to its 'mother' or reference disciplines, namely Public Administration and Management (Van der Waldt 2009:16), which emerged in 1887 in the USA, and Development Studies (Vermaak 2004:8), which emerged with modernisation, underdevelopment, and growth and catch-up theories of the 1950s and Rostow's Limits to Growth perspective in the 1960s, DRM is still a very young discipline.

It should be noted that there is as yet no clear consensus regarding the 'official' naming of the discipline. Two main streams of thought are evident, namely Disaster Risk Reduction (DRR) and Disaster Risk Management (DRM). The particular stream that the author prefers, as was endorsed by D. van Niekerk in an interview on 28 May 2012, is that the more appropriate name for the discipline is DRM, since DRR refers more to the outcome or result of effective management. DRR has a strong developmental end-focus, whilst DRM is demarcated as an integrated multisectoral and multidisciplinary process for the planning 
and implementation of measures for risk reduction, disaster recovery and rehabilitation. DRM also better accommodates all the management processes associated with policy development, general governance issues, the functioning of structures, and strategy and programme development and implementation.

\section{The interdisciplinary nature of Disaster Risk Management}

Some observers argue that due to the scale of complexity of research problems, scientists have to move beyond the confines of their individual disciplines and explore new models for science. In this regard, Eddy (2005:3) refers to the 'antedisciplinary' nature of science because of the need to have a multidisciplinary team focus with regard to research projects.

Assessing reference discipline implications for an emerging discipline assists researchers in their understanding of existing disciplines and helps to uncover precisely how existing knowledge can be incorporated into new theories and concepts (Gibbons et al. 1994:45). Identifying and understanding the contributions of reference disciplines provides a foundation of support for a new discipline in the existing research community. By referencing disciplines, the contributions of existing knowledge can be formally recognised and a logical link to the new discipline is provided. Researchers in the existing discipline communities can follow these links and develop a measure of acceptance and recognition for the new discipline. Without this linkage, existing disciplines may question the grounding theories of a new discipline and dismiss its importance (Liles et al. 1995).

Study fields and established disciplines constantly adjust, rediscover and enrich themselves by 'borrowing' useful theories, approaches, methodology, principles and concepts from established, related disciplines. It should be noted that, in the case of DRM, related disciplines such as Environmental Sciences, Public Administration and Management, Geography, Sociology, and Communication Studies have themselves grown increasingly fragmented with various subdomains in recent years. DRM therefore needs to co-evolve with these related disciplines and with systems of professions in order to further adjust and nurture its own theoretical foundations and methodology. Holloway (2009:104) in this regard refers to the 'emerging cross-cutting' nature of DRM. It is argued that without this acknowledgement the DRM scholar would have a highly restricted vantage point with regard to both phenomena identification and problem-solving applications in the field. It is furthermore argued that the very survival of an applied, emerging discipline such as DRM is dependent on the degree to which it succeeds in adjusting and applying itself to changing macro-conditions and circumstances ('usefulness'). Failure to do this could create the danger of becoming impoverished and ultimately even obsolete (Van der Waldt 2009).
Interdisciplinarity involves the combining of two or more academic fields into one single discipline, and an interdisciplinary field crosses traditional boundaries between disciplines and theoretical models as new needs and professions emerge (Augsburg 2005).

To probe the interdisciplinary nature of DRM, the next section explores the content or research subfoci of the discipline by means of a content analysis of its knowledge products. This analysis is critical in determining the categories to be used in a further content analysis of Jàmbá papers (Figure 1). Both content analyses will provide the necessary insight into the disciplinary status of DRM as the focus of this paper. It should be noted that the content analysis was done on a particular case (a single unit of analysis) and findings or results emanating from this limited perspective can thus not be generalised to a larger population (that is, the nature and status of DRM internationally).

\section{Methodology: Content analysis}

Content analysis is a widely-used qualitative research technique for the interpretation of meaning from the content of text data (Allen \& Reser 1990:253; Harwood \& Garry 2003:483). Content analysis, as an empirical, methodological, controlled analysis, facilitates the subjective interpretation of the content of text data through the systematic classification process of coding and identifying themes or patterns (Hsieh \& Shannon 2005:1278; Mayring 2000:2). Neuendorf (2002) and Patton (2002:453) also refer to it as a 'sense-making effort' that attempts to identify both core consistencies and meanings. It allows researchers to understand social reality in a subjective but scientific manner. It can be a useful technique for the discovery and description of the focus of individuals, groups, institutional, or social attention (Krippendorff 1980; Weber 1990).

Qualitative content analysis is mainly inductive, grounding the examination of topics and themes, as well as the inferences drawn from them, in the data. Samples for qualitative content analysis usually consist of purposively selected texts which can inform the research questions being investigated (Berg 2001). The qualitative approach usually produces descriptions or typologies, along with expressions from

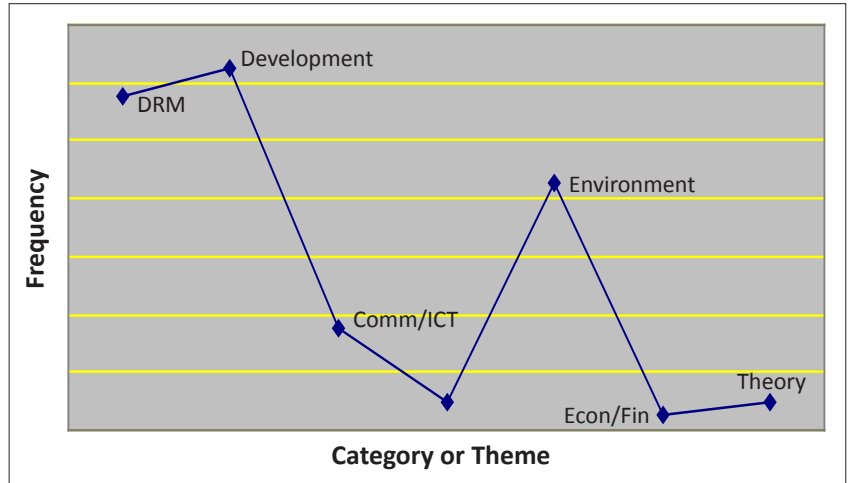

Source: Developed by author for article

DRM, Disaster Risk Management; Econ, economics; Fin, finances.

FIGURE 1: Content analysis of themes covered by Jàmbá. 
subjects reflecting how they view the social world. It focuses on unique themes that illustrate the range of the meanings of the phenomenon rather than the statistical significance of the occurrence of particular texts or concepts (Smith 1975:218).

Qualitative content analysis involves a process designed to condense raw data into categories or themes based on valid inference and interpretation (Hsieh \& Shannon 2005; Patton 2002). To support valid and reliable inferences, qualitative content analysis involves a set of systematic and transparent procedures for the processing of data. Depending on the goals of the study, content analysis may be more flexible or more standardised, but it can most often be divided into the following steps, beginning with preparing the data and proceeding through to writing up the findings in a report (Miles \& Huberman 1994; Tesch 1990).

\section{Unit of analysis and coding}

A unit of analysis refers to the basic unit of text to be classified during content analysis (De Wever et al. 2006:10). Qualitative content analysis usually uses individual themes as the unit for analysis (Minichiello et al. 1990). The preparation phase starts with selection of the unit of analysis (Cavanagh 1997:8). The sample must be representative of the universe from which it is drawn (Tesch 1990).

A coding scheme (categories or coding units) can be derived from three sources: the data, previous related studies, and theories (Miles \& Huberman 1994). The adoption of coding schemes developed in previous studies has the advantage of supporting the accumulation and comparison of research findings across multiple studies (Lincoln \& Guba 1985). In this paper, when describing the analysis process the term 'category' is used, since the unit of analysis is the content of journal papers. The purpose of creating categories is to provide a means of describing the phenomenon, to increase understanding and to generate knowledge (Cavanagh 1997:9; Dey 1993). Each category is named using contentcharacteristic words. Subcategories with similar events and incidents are grouped together as categories and categories are grouped together into main categories (Dey 1993; Patton 2002:503; Schilling 2006:32).

\section{Content analysis 1: Determining categories of Disaster Risk Management}

To enable a content analysis of Jàmbá papers, it is necessary to determine the categories according to which the content of the papers will be classified. A (pre-)content analysis was thus undertaken of key foci of DRM as portrayed by qualifications, programmes, research reports and United States Agency for International Development (USAID) knowledge products, the content (curriculum), as well as the outcomes and assessment of the following formal and nonformal programmes, as offered by the African Centre for Disaster Studies, attached to North-West University:

- Certificate programme in Disaster Risk Reduction.

- Basic course in Disaster Reduction.
- Advanced course in Disaster Reduction.

- Disaster Risk Management Planning.

- Implementation of the Disaster Management Act 57 of 2002 and the National Disaster Management framework (South Africa).

- Masters in Development and Management: Curriculum Disaster Risk Reduction.

An addition to the list above, completed research reports ( $n=10$ ) from the period 2007-2011 as well as completed Masters studies $(n=12)$ and doctoral studies $(n=2)$ at NorthWest University were analysed.

The above qualifications, programmes, research reports and postgraduate studies revealed the units of analysis or categories that could be utilised for purposes of a content analysis of the papers of Jàmbá. Table 2 below reflects the DRM categories identified as well as the branches of science from which appropriate knowledge could be extracted. Also in Table 2 below the findings in terms of frequency are reflected. The branch of science is indicated to determine whether DRM could be categorised as an applied social science.

This analysis illustrates the appropriateness of classifying DRM as an applied $(n=5)$ social science $(n=8)$.

\section{Findings: Categories}

This analysis clearly revealed the interdisciplinary nature of DRM. Nine categories were identified based on the content of the research reports, qualifications, training programmes and USAID knowledge products. The identification of these nine categories enabled a secondary content analysis of Jàmbá papers, as discussed below.

\section{Content Analysis 2: Jàmbá papers}

One of the key indicators of the status of a discipline is the quality of research in its journals (Cameron \& McLaverty 2007:70; Moed 2005; Reeves, Herrington \& Oliver 2005:98). An analysis of the nature and quality of papers published reveals whether research enhances theory development and knowledge in the discipline or whether they are practicallyoriented.

Jàmbá is hosted by the African Centre for Disaster Studies, North-West University and is the only rated and South African accredited journal in the field (accredited journals are recognised research output which meet specified criteria and therefore qualify for subsidisation by the Department of Education). As such, it provides valuable insight into the disciplinary status of DRM in South Africa.

TABLE 2: Findings: Frequency.

\begin{tabular}{ll}
\hline Branch of science reflected in content & Frequency \\
\hline Applied Sciences & 5 \\
Humanities & 1 \\
Natural Sciences & 1 \\
Social Sciences & 8 \\
\hline
\end{tabular}

Source: Developed by author for study 


\section{Unit of analysis}

All six editions of Jàmbá published thus far were used as sample - thus $100 \%$ of the total or target population. Table 3 below indicates the volume and number of Jàmbá editions as well as the number of papers that were utilised as units of analysis.

For the purposes of analysis, two of the variables identified by Cameron and McLaverty (2007:78), namely 'topic' and 'methodology', were utilised as units or categories. Assessment and interpretation of these variables make explanatory and critical and statistical analysis possible.

\section{Variable 1: Topic}

The research topic simply depicts what DRM authors are writing about. Stallings and Ferris (in Cameron \& McLaverty 2007:79) indicate that this variable is effective for the description of research characteristics. For the purposes of content analysis, the themes (or content categories) as reflected in Table 4 were utilised in order to determine the nature of the paper topics. In cases where papers deal with two or more constructs (for example, 'Disaster Risk through Vulnerability Assessment: An Agricultural Perspective'), the focus of the paper is indicated as $n=1$ and the locus thereof $n=0.5$. As per the example 'vulnerability assessment' (focus) was allocated $n=1$ in theme or category 'Management: Risk' and 'Agriculture' (locus) was allocated $n=0.5$ as part of theme 'Environment'. Table 5 below reflects the DRM themes as well as frequency responses.

\section{Findings}

The findings indicate the broad nature of current research in the discipline. The strong emphasis on environmental issues $(n=8.5)$, Disaster Risk Management (cumulative $n=11.5$ ) and Development ( $n=12.5$ ) confirms the social science classification and current knowledge production focus of the discipline. The fact that only one paper out of the 35 focused on theory-building is further indicative of the relatively low maturity level of the discipline as far as its theoretical underpinnings are concerned.

\section{Variable 2: Methodology}

According to Perry and Kraemer (in Cameron \& McLaverty 2007:85), this variable reflects the general methods and approaches of enquiry used in research. It is designed to answer the question: 'what methodologies are employed to conduct research?' For the purposes of this content analysis, the empirical nature of the papers was analysed to determine whether the research design and methods of data collection were qualitative, quantitative or mixed-mode (labelled as 'empirical'), or whether they were 'desktop' in nature. Desktop papers are categorised as those studies which consist primarily of secondary research (information obtained from databases, journals, books, policies, and research reports) and which do not contain any empirically tested or verified research component. This definition of desktop papers also presumes that no new theoretical model or framework has been developed.
TABLE 3: Jàmbá editions and number of papers.

\begin{tabular}{ll}
\hline Jàmbá: Volume \& Number & Number of papers \\
\hline Vol. 1 No. 1 & 7 \\
Vol. 2 No. 1 & 5 \\
Vol. 2 No. 2 & 4 \\
Vol. 2 No. 3 & 8 \\
Vol 3. No. 1 & 5 \\
Vol 3. No. 2 & 6 \\
\hline Total & N=35 \\
\hline
\end{tabular}

Source: Developed by author for study

\section{Results}

Please see Figure 2.

\section{Findings}

Forty per cent (14 of $n=35$ ) of all papers contained an empirical component. This result is surprising in the sense that one would expect that an emerging discipline with relatively low maturity levels in terms of theory development and knowledge production, would contain more desktop papers. By comparison, in the discipline of Public Administration, papers published in the two main accredited journals in South Africa, namely the Journal of Public Administration and Administratio Publica, reflected that $41.5 \%$ (113 of $n=270)$ of all papers had an empirical research component (Cameron \& McLaverty 2007:87). Jàmbá is thus already on par with journals in related, more mature disciplines. The nature of data collection methods also illustrates the relatively high maturity levels of research capacity. Data collection methods range from focus group interviews, questionnaires, case studies and time series analysis to participatory action research (PAR). From the above one might argue that Jàmbá represents a solid attempt on the part of the host, the African Centre for Disaster Studies, to provide a platform for the sharing of research and views on DRR on the African continent.

\section{Disciplinary status of Disaster Risk Management: Applying a focus area maturity model}

Philosophers of science have given considerable attention to the logic of completed scientific systems. The seminal work of Thomas Kuhn (1970) on paradigms in science, Norwood's (1958) 'logic of discovery', and Hanson's (1958) 'patterns of discovery' uncover the philosophical aspects of discovery in general and research in particular. Hanson, for example, shows that there is a logical pattern involved in finding theories as much as in using established theories to make deductions and predictions.

To understand complex phenomena, a discipline requires a comprehensive body of knowledge or a thought framework as a cognitive tool for knowledge production. Due to the highly dynamic nature of societal phenomena, an established discipline from one of the branches of science, namely Humanities, Social Sciences, Natural Sciences, or Applied Sciences, may not have adequate theories, methodology, models, concepts, and approaches of knowledge production to allow them to study a particular phenomenon adequately. 
TABLE 4: Content analysis of formal and non-formal qualifications and programmes.

\begin{tabular}{|c|c|c|}
\hline $\begin{array}{l}\text { Subject content of DRM } \\
\text { (Categories) }\end{array}$ & Description & $\begin{array}{l}\text { Branch of } \\
\text { science }\end{array}$ \\
\hline \multicolumn{3}{|l|}{ Management: } \\
\hline Planning & $\begin{array}{l}\text { - Planning principles and techniques } \\
\text { - Scenario development } \\
\text { - Forecasting } \\
\text { - Basic, corporate and contingency } \\
\text { - Slans } \\
\text { Spatial planning }\end{array}$ & S \\
\hline Risk & $\begin{array}{l}\text { - Hazards } \\
\text { - Risk assessments } \\
\text { - Vulnerability }\end{array}$ & \\
\hline General & $\begin{array}{l}\text { - Project management } \\
\text { - Establish and manage disaster } \\
\text { management structures } \\
\text { - Disaster response and recovery: } \\
\text { resource utilisation }\end{array}$ & \\
\hline \multicolumn{3}{|l|}{ Development: } \\
\hline $\begin{array}{l}\text { human (socio-cultural) } \\
\text { focus }\end{array}$ & $\begin{array}{l}\text { - Community dynamics and } \\
\text { - Cemographics } \\
\text { - Cummunities at risk/marginalised } \\
\text { - Indigenous knowledge-base } \\
\text { - Psychology } \\
\text { - Developmental and self-help projects } \\
\text { - Sustainable livelihood assessments } \\
\text { - Building resilience and enhancing } \\
\text { livelihoods }\end{array}$ & $\mathrm{S} / \mathrm{H} / \mathrm{A}$ \\
\hline Communication \& ICT & $\begin{array}{l}\text { - Crisis communication } \\
\text { - Advocacy } \\
\text { - Communication technology } \\
\text { - Community participation facilitation } \\
\text { - MIS } \\
\text { - GIS (incl. Statistics) } \\
\text { - Early-warning systems and forecasting } \\
\text { - Information management }\end{array}$ & $\mathrm{S} / \mathrm{N}$ \\
\hline Health \& Safety & $\begin{array}{l}\text { - Nutrition } \\
\text { - Epidemics } \\
\text { - Diseases } \\
\text { - Unsafe living conditions and practices }\end{array}$ & A \\
\hline Environment & $\begin{array}{l}\text { - Climate change \& weather patterns } \\
\text { - Adaptation } \\
\text { - Agriculture and food security } \\
\text { - Natural resources, including water } \\
\text { - Ecology } \\
\text { - Physical and natural phenomena }\end{array}$ & S/A \\
\hline $\begin{array}{l}\text { Economy \& Financial } \\
\text { aspects }\end{array}$ & $\begin{array}{l}\text { - Economic conditions } \\
\text { - Financial risks } \\
\text { - Costs of disasters } \\
\text { - Financial resources and budgeting } \\
\text { - Financial reserves }\end{array}$ & S/A \\
\hline Education \& Training & $\begin{array}{l}\text { - Skills development } \\
\text { - Institutional people capacity } \\
\text { - Professional development } \\
\text { - Career development } \\
\text { - Training programmes (i.e. UNDP) }\end{array}$ & S \\
\hline Government \& Politics & $\begin{array}{l}\text { - Statutory and regulatory framework } \\
\text { - Guidelines for operational organisational } \\
\text { structures and arrangements } \\
\text { - IDP \& LED alignment } \\
\text { - Civil defence agencies } \\
\text { - Institutional resource allocation } \\
\text { - Disasters and political dynamics } \\
\text { - Policy agenda } \\
\text { - Predisaster risk reduction and post- } \\
\text { disaster recovery } \\
\text { - Disaster risk reduction as a human right } \\
\text { - International policy } \\
\text { - International aid and relief } \\
\text { - International treaties and protocols }\end{array}$ & S/A \\
\hline DRR \& DRM Theory & $\begin{array}{l}\text { - Theory and theory development } \\
\text { - Model building (i.e. Pressure model, } \\
\text { Release model, etc.) }\end{array}$ & S \\
\hline
\end{tabular}

Source: Developed by author for study

A, Applied Sciences; H, Humanities; N, Natural Sciences; S, Social Sciences; DRM, Disaste Risk Management; DRR, Disaster Risk Reduction; IDP, Integrated Development Plan; UNDP, United Nations Development Programme, MIS, management information system; GIS, geographic information system.
TABLE 5: Research results.

\begin{tabular}{ll}
\hline DRM themes & Frequency $(=\boldsymbol{n})$ \\
\hline Disaster Management: Planning & 2.0 \\
Disaster Management: Risk & 6.5 \\
Disaster Management: General & 3.0 \\
Development: human (socio-cultural) focus & 12.5 \\
Communication \& ICT & 3.5 \\
Health \& Safety & 1.0 \\
Environment & 8.5 \\
Economy \& Financial aspects & 0.5 \\
Education \& Training & 0 \\
Government \& Politics & 0 \\
DRR \& DRM Theory & 1.0 \\
\hline
\end{tabular}

Source: Developed by author for study

DRM, Disaster Risk Management; DRR, Disaster Risk Reduction; ICT, information and communications technology.

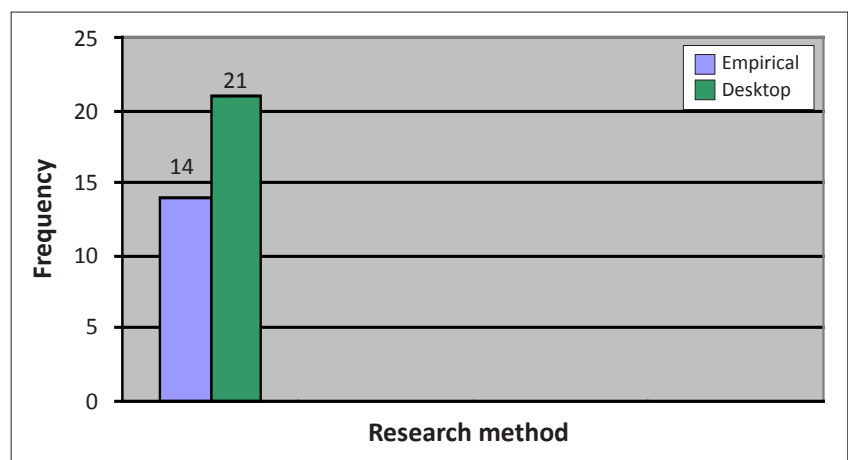

Source: Developed by author for study

FIGURE 2: Distribution of papers according to research method.

As a result a unique field of study may emerge - typically as a branch from one of the established disciplines. Should there be adequate impetus and interest in the field - usually stimulated by needs of industry - a distinctive corpus of knowledge emerges (Nachmias \& Nachmias 1976:4). Therefore, over time, a field or branch of study may progress through various maturity levels to become a new entrenched discipline. Maturation of an independent academic discipline is a time-consuming process, in which a field of study acquires the status of a formal discipline, step by step. A field of study can be regarded as 'matured' if it relies on its own unifying theory and knowledge base (Lowenstein 2004:30).

Theorists usually simply differentiate between wellestablished (mature) disciplines that have a long history with a well-established set of theories and approaches, and new emerging fields - supported by only a few universities and publications. An incremental maturity process is usually evident where knowledge production regarding a certain phenomenon gradually evolves to accommodate best practices, theories, models, and approaches associated with more mature, related disciplines.

Measurement is a foundational component of scientific enquiry, providing an objective framework or structure for contributing to the body of human knowledge (Grim 2009:69). Without this framework, it would be difficult to describe phenomena objectively, and to compare and monitor change within its parameters. As such, a maturity model could provide valuable insight into disciplinary status. 
Various maturity models exist and are commonly applied in organisational structure theory and Project Management. In 1986, the U.S. Department of Defense developed the Capability Maturity Model (CMM) (Grim 2009:70). Over time, the maturity model approach has become well respected and widely adopted in many disciplines.

The majority of maturity models are fixed-level models which distinguish a fixed number, of generic maturity levels (usually around five). Each maturity level is associated with a number of processes that have to be implemented (de Bruin $e$ t al. 2005). Fixed-level models are well-suited to benchmarking, placing an organisation at a determined maturity level by assessing the extent to which the associated processes are implemented, but they are less suited to incremental improvement, as they cannot express interdependencies between the processes making up the maturity levels. More suited to incremental improvement of functional domains, such as in and between disciplines, are the so-called 'focus area' maturity models (Grim 2009:70).

Focus area maturity models are based on the concept of a number of focus areas that have to be developed in order to achieve maturity in a functional domain. The identification of the exact focus areas depends on the functional domain. A focus area maturity model defines, for each of its focus areas, a series of development steps in the form of progressively mature capabilities (Steenbergen et al. 2010:319).

It is argued that the application of the principles of a maturity model provides valuable insight into the incremental development of a discipline. The author proposes that an adjusted focus area maturity model be applied to gauge the disciplinary standing of DRM. Table 6 below suggests the application of a 5-stage focus area maturity model to 'measure' the status of DRM. The six characteristics of a discipline, as identified by Liles et al. (1995) in Table 1 above, were used as focus areas to populate the maturity model. A literature study did not reveal any similar study or example where a maturity model was applied to determine the status of a discipline. An indication of the maturity level can therefore not be substantiated, and is merely a reflection of the author's perceptions based on general observations and the content analyses of knowledge products of DRM.

By triangulating the findings from content analyses 1 and 2 , one may conclude that DRM is on a very steep growth curve, with surprisingly high levels of maturity. It is clear that the discipline has leap-frogged adjacent disciplines and adequately incorporated relevant knowledge into its corpus. As can be expected, the level of theory development and testing, model building and philosophical underpinnings are relatively low. The data sample is perhaps too small to be conclusive as far as the status of the discipline in South Africa is concerned, although the findings definitely illustrate a particular trend. A more detailed analysis of the status of the discipline in South Africa should include:
TABLE 6: DRM disciplinary status: Applying a Focus Area Maturity Model.

\begin{tabular}{|c|c|c|c|c|c|}
\hline \multirow{2}{*}{$\begin{array}{l}\text { Focus Areas } \\
\text { (Characteristics of a discipline) }\end{array}$} & \multicolumn{5}{|c|}{ Maturity Level } \\
\hline & $\begin{array}{c}1 \\
\text { (low) }\end{array}$ & 2 & 3 & 4 & $\begin{array}{c}5 \\
\text { (high) }\end{array}$ \\
\hline 1. Focus of study & - & $x$ & - & - & - \\
\hline 2. Paradigm or world view & $x$ & - & - & - & - \\
\hline 3. Reference disciplines & - & - & - & $x$ & - \\
\hline 4. Principles and practices & - & - & $x$ & - & - \\
\hline 5. Active research agenda & - & - & - & $x$ & - \\
\hline 6. Education and professionalism & - & - & - & $x$ & - \\
\hline
\end{tabular}

Source: Developed by author for study

DRM, Disaster Risk Management.

- Foci and methodology of completed postgraduate studies at all tertiary institutions, both public and private, which have DRM training programmes and qualifications.

- A representative sample of research reports and knowledge products.

- Research foci by scholars attached to tertiary institutions.

- Knowledge production contributions of practitioners attached to non-governmental organisations (NGOs), disaster management centres, and professional bodies and societies such as the Southern Africa Society for Disaster Reduction (SASDiR) and Rescue South Africa.

To reflect on the disciplinary status of a field of study from a maturity point of view implies a vast overview and insight into all the intricacies associated with the discipline. Such a reflection should, arguably, be approached from various vantage points or perspectives - each with differing levels of maturity and with associated interdependencies. Such a perspective could, for example, include the following:

- Quantitative perspective (criteria): How many postgraduate studies were completed, papers and scientific reports published and policies made?

- Qualitative perspective: To what extent did this new discipline contribute to mainstream risk issues in governance, to adjusting organisational culture and ethos, and to the philosophic underpinnings in South Africa?

- Time perspective: What kind of growth trends emerged over time and how did the relevance of the discipline increase in the last decade?

- Paradigm perspective: What is the nature of the particular theoretical vantage point; what is the main paradigm, and what is the nature of theory development?

Due to the unique politico-historical, socio-economic and demographic challenges that South Africa faces, one may argue that emerging applied disciplines are likely to be influenced by the realities observed and addressed by scholars within the field. Applied disciplines such as Public Management and DRM are typically in 'fire-fighting' mode to address the vast realities and demands of practice and do not always have the luxury to reflect on academic advancement and theory-building endeavours. The focus rather is placed on vocational training and up-skilling of practitioners in order to deal with the immense challenges associated with the establishment of governance structures and policies, informal settlements, health and other risk issues. In line with the notion of a developmental state and the four key 
attributes articulated by Vision 2030 of the National Planning Commission (2011) and the African National Congress's strategies and tactics vision for the developmental state, DRM as an applied science could contribute significantly towards a strategic orientation, the building of leadership capacity, the state's organisational capacity and the technical capacity of practitioners. The latter refers to the acquired ability through training, orientation and leadership of practitioners in disaster risk related functions.

The secondary focus of the paper is to reflect on the prospects for a unifying theory in DRM. Based on the content analyses, the following section explores these prospects.

\section{Prospects for a unifying theory in Disaster Risk Management}

According to Dubin (1969) and Tomic (2010:714) a scientific theory must be a simple unifying idea that does not include anything unnecessary. A body of knowledge is usually only called a theory once it has a minimum empirical basis, according to certain criteria such as being consistent with pre-existing theory, to the extent that said pre-existing theory was experimentally verified (although it will often show pre-existing theory to be wrong in an exact sense), and also in being supported by many strands of evidence, rather than a single foundation, ensuring that it is probably a good approximation, if not totally correct (Babbie \& Mouton 2011:10; Jones 1954). Scientific observations are guided by scientific theories, and through the testing of theories new scientific discoveries are made (Tomic 2010:714).

The quest for unifying theories in various disciplines is not new: Jones (1954) searched for a unifying theory of Political Geography; Tomic (2010) researched the philosophy of information as a unifying theory of information sciences; Henriques (2003) and Henriques and Cobb (2004) proposed a unifying theory for Psychology; Baldwin (2002) provided a synthesis of Mead's work on a unifying theory for Sociology; Hempel (1952), and Greenwood and Eggins (1995:14) concluded that one of the biggest dilemmas in Public Administration is that there is no unifying theory or paradigm in the field. A unified theory provides fertile ground for scientific and philosophical inquiry on multiple levels of analysis, and it may play a central role in helping the discipline of DRM fulfil its constructive potential.

There seems to be relative consensus that DRM does not yet have a distinct and unique body of knowledge, methodology and unifying theory (Cardona 1999; Luhmann 1993; Varley 1994). Although scholars such as Quarantelli (1954: 267-275), Moore (1956:734-737), Bogard (1989), and McEntire (2003) made early attempts to develop a theory of disaster management, Jeggle (2001:316) is of the opinion that due to continuous evolution in viewpoints there is not yet a common understanding of what disaster management entails.

It is often assumed that DRM, by virtue of its complexity and breadth, cannot be organised successfully into a single, overarching system. The framing of the study of disasters and risk reduction is, however, essential for the recognition thereof as a distinct discipline. This is confirmed by Wisner et al. (2012:18-33) who emphasise the need to frame natural hazards, DRM and DRR, and express the desire to develop a holistic view (paradigm) of the discipline.

The need for a unifying theory of DRM may be recognised in the literature (for example, both in journal content and the praxis of the field). What might such a theory look like? As reflected in Box 1 above, DRM is not a discipline with clear boundaries that would, at the moment, describe its research questions, theories and methods in a unified manner. It is instead a complex, dynamic field that addresses many different research problems grounded in a variety of theories and methodologies. This results in a plurality of theoretical and methodological subdomains of Applied Sciences, Social Sciences, Humanities, and Natural Sciences. To develop a unifying theory would thus imply the seeking of relationships between the philosophical underpinnings and knowledge bases of these various subdomains.

DRM's nature does not seem to be a mono-logistic, objecttheory of disasters based on a particular theoretical and methodological frame suitable for explaining all the different dimensions of disasters. It might rather be a meta-theory that would study the ways in which the varying subdomains deal with the phenomenon of disasters. A unifying meta-theory would also analyse the possibilities of relating the different subdomains, and their results, to each other (Tomic 2010:714). It falls outside the scope of this paper to attempt to develop a unifying theory and therefore steps are merely proposed that may be followed in a search for such a unifying theory.

- Step 1: Conduct comparative analyses of the knowledge subdomains in adjacent disciplines and identify their mutual connections.

- Step 2: Uncover the epistemology or philosophical theory of knowledge of each of the subdomains. The epistemology would possibly reflect on the principles of approaching DRR and DRM in each of the particular subdomains and relate each of these approaches to some of the traditional philosophical problems associated with the field. From content analysis 1 it is evident that some epistemological theories are already implicitly applied in the field of DRM, such as those developed by related disciplines such as Sociology, Public Administration and Management, and Development Studies.

- Step 3: Commonalities in the paradigms or underlying philosophies of the reference disciplines may now become a unifying theory for DRM. Such meta-theory would possibly analyse how the specific subdomains may be unified under a common paradigm.

These steps are schematically depicted in Figure 3 below. Models such as the Pressure Model or Disaster Crunch Model (Blaikie et al. 1994, as adapted by Wisner et al. 2012) should be further developed to serve as a framework for such a unifying theory. Scholars in the field may also consider the 


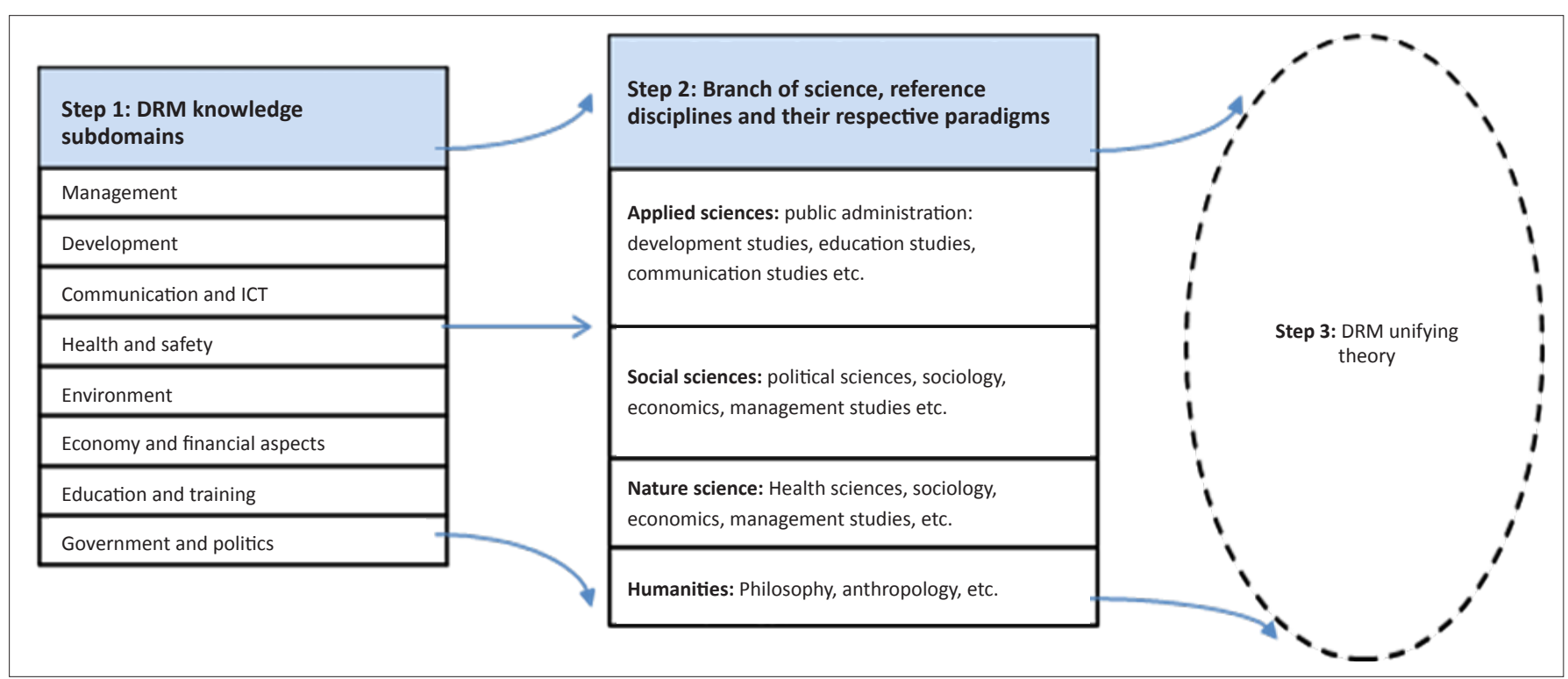

Source: Developed by author for article

DRM, Disaster Risk Management; ICT, information and communications technology.

FIGURE 3: Steps towards a unifying theory for DRM.

utilisation of knowledge technology to frame complexities associated with concepts, models and theories, such as the Tree of Knowledge (ToK) System (Chaisson 2001) as well as the utilisation of methodology and principles of transdisciplinary research.

Due to the multitude of competing paradigms within reference disciplines it is highly unlikely that a unifying theory for DRM is attainable and it is in all likelihood also not advisable, because of its potentially limiting scope with regard to addressing complex DRM-related problems. The best way forward is probably, as the science philosopher Popper $(1959 ; 1972)$ suggested, that one should not take disciplines too seriously. What matters are problems rather than disciplines; the latter 'exist largely for historical reasons and administrative convenience'. One should therefore not try to search for a unifying theory, but rather accept DRM as an interdisciplinary study field. The key is thus not to think from within a discipline about DRM problems but to think in between disciplines about DRM problems.

\section{Conclusion}

The purpose of this paper was to explore the disciplinary status of DRM as an emerging applied social science and to consider prospects for the establishment of a unifying theory or philosophical underpinning for the discipline. The exploration of the disciplinary status was facilitated by content analyses of knowledge products of the discipline, including study material, research reports, and completed postgraduate research in order to determine the typical categories or specialist areas or domains (curricula) of the discipline as well, as a subsequent content analysis of Jàmbá articles. The research findings were then plotted on a focus area maturity model to facilitate opinion formulation regarding the disciplinary status of DRM.
The findings reveal surprisingly high levels of maturity and set the parameters for a continuous discourse regarding the current disciplinary status of DRM in South Africa. In view of the proliferation of publications, qualifications, programmes and research reports in the field, the exponential growth in related professions, the establishment of a comprehensive statutory and regulatory framework governing disaster risk issues in South Africa, and the willingness of scholars to engage theorists from related disciplines, it is argued that the maturity curve to be become a full-fledged mature discipline, is approaching at a rapid rate.

\section{Acknowledgments Competing interests}

The author declares that he has no financial or personal relationship(s) which may have inappropriately influenced him in writing this paper.

\section{References}

Abbott, A., 2001, Chaos of Disciplines, University Of Chicago Press, Chicago. Alexander, J.C., 2011, Performance and Power, Polity, Cambridge.

Allen, B. \& Reser, D., 1990, 'Content analysis in library and information science research', Library \& Information Science Research 12(3), 251-260.

Augsburg, T., 2005, Becoming interdisciplinary: an introduction to interdisciplinary studies, Kendall/Hunt Publishing, Dubuqe, lowa.

Babbie, E.R. \& Mouton, J., 2011, The practice of social research, Oxford University Press, London.

Baldwin, J.D., 2002, George Herbert Mead: A unifying theory for Sociology, Kendall/ Hunt Publishing Company, New York.

Becher, T., 1987, 'The Disciplinary Shaping of the Profession', in B.R. Clark (ed.), The Academic Profession: National, Disciplinary, and Institutional Settings, pp. 271303, University of California Press, Berkeley.

Benardete, J., 1991, The Rhetoric of Morality and Philosophy: Plato's Gorgias and Phaedrus, University of Chicago Press, Chicago.

Berg, B.L., 2001, Qualitative Research Methods for the Social Sciences, Allyn and Bacon, Boston.

Biglan, A., 1973, 'The Characteristics of Subject Matter in Different Academic Areas', Journal of Applied Psychology 58, 195-203. http://dx.doi.org/10.1037/h0034701

Blaikie, P., Cannon, T., Davis, I. \& Wisner, B., 1994, At risk: Natural hazards, people vulnerability, and disasters, Routledge, London. 
Bogard, W.C., 1989, 'Bringing Social Theory to Hazards Research: Conditions and Consequences of the Mitigation of Environmental Hazards', Sociological Perspectives 31, 147-168. http://dx.doi.org/10.2307/1389080

Cameron, R. \& McLaverty, L., 2007, 'Public Administration research in South Africa: An assessment of journal publication, 1994-2006', Administratio Publica 15(2), 69-96.

Cardona, O.D., 1999, 'Environmental management and disaster prevention: Holistic risk assessment and management', in I. Ingleton (ed.), Natural Disaster Management, pp. 151-173, Tudor Rose, London.

Cavanagh, S., 1997, 'Content analysis: concepts, methods and applications', Nurse Researcher 4, 5-16.

Chaisson, E.J., 2001, Cosmic evolution: The rise of complexity in nature, Harvard University Press, Cambridge.

De Bruin, T., Freeze, R., Kulkarni, U. \& Rosemann, M., 2005, 'Understanding the Main Phases of Developing a Maturity Assessment Model', in Proceedings of the 16th
Australasian Conference on Information Systems, Sydney, viewed 01 September Australasian Conference on Information Systems, Sydney, viewed 01 September
2012, from http://eprints.qut.edu.au/25152/1/Understanding_the_Main_ Phases_of_Developing_a_Maturity_Assessment_Model.pdf.

Denning, P.J., 1989, 'Computing as a Discipline', Communications of the ACM 32(1) 9-23. http://dx.doi.org/10.1145/63238.63239

De Wever, B., Schellens, T., Valcke, M. \& Van Keer, H., 2006, 'Content analysis schemes to analyze transcripts of online asynchronous discussion groups: A review', Computer \& Education 46, 6-28. http://dx.doi.org/10.1016/j. A review', Computer
compedu.2005.04.005

Dey, I., 1993, Qualitative Data Analysis. A User-Friendly Guide for Social Scientists, Routledge, London. http://dx.doi.org/10.4324/9780203412497

Doheny, M.O., Cook, C. \& Stopper, M., 1987, The Discipline of Nursing: an introduction, 2nd edn., Appleton \& Lange, Norwalk, Connecticut.

Dubin, R., 1969, Theory Building, Free Press, New York.

Eddy, S.R., 2005, 'Antedisciplinary Science', PLOS Computational Biology 1(1), 3-4. http://dx.doi.org/10.1371/journal.pcbi.0010006

Foucault, M., 1979, Discipline and punish: The birth of the prison, Vintage, New York.

Gibbons, M., Limoges, C., Nowotny, H., Schwartzman, S., Scott, P. \& Trow, M., 1994, The new production of knowledge: the dynamics of science and research in contemporary societies, Sage, London.

Greenwood, J. \& Eggins, H., 1995, 'Shifting sands: teaching Public Administration in a climate of change', Public Administration 73(1), 143-163.

Grim, T., 2009, 'Foresight Maturity Model (FMM): Achieving best practices in the foresight field', Journal of Future Studies 13(4), 69-80.

Hanson, N.R., 1958, Patterns of Discovery: An Inquiry into the Conceptual Foundations of Science, Cambridge University Press, Cambridge.

Harwood, T.G. \& Garry, T., 2003, 'An overview of content analysis', The Marketing Review 3, 479-498. http://dx.doi.org/10.1362/146934703771910080

Hempel, C.G., 1952, 'Fundamentals of concept formation in the empirical sciences', International Encyclopedia of Unified Science 2(7), 36

Henriques, G.R., 2003, 'The tree of knowledge system and the theoretical unification of psychology', Review of General Psychology 7, 150-182. http://dx.doi. org $/ 10.1037 / 1089-2680.7 .2 .150$

Henriques, G.R. \& Cobb, H.C., 2004, 'Introduction to the special issues on the unified Theory. Wiley Periodicals', Journal of Clinical Psychology 60(12), 1203-1205.

Holloway, A., 2009, 'Crafting Disaster Risk Science: Environmental and geographical science sans frontiéres', Gateways. International Journal of Community Research and Engagement 2, 98-118.

Hsieh, H.F. \& Shannon, S.E., 2005, 'Three approaches to qualitative content analysis', Qualitative Health Research 15(9), 1277-1288. http://dx.doi. org/10.1177/1049732305276687

Jeggle, T., 2001, 'The Evolution of Disaster Reduction as an international strategy: Policy Implications for the future', in U. Rosenthal, R.A. Boin \& L.K. Comfort, Managing Crises: Threats, Dilemmas, Opportunities, pp. 316-341, Charles C Thomas Publishers, Illinois.

Jones, S.B., 1954, 'A unified field theory of Political Geography', Annals of the Association of American Geographers XLIV(2), 111-123.

Keen, P.G.W., 1980, 'MIS Research: Reference Disciplines and Cumulative Tradition', in Proceedings of the First International Conference on Information Systems, Philadelphia, Pennsylvania, December 1980, Society for Management Information Systems, Philadelphia, 09-18.

Krippendorff, K., 1980, Content Analysis: An Introduction to Its Methodology, Sage, Newbury Park, CA

Kuhn, T.S., 1970, The Structure of Scientific Revolutions, 2nd edn., The University of Chicago Press, Chicago.

Liles, D.H., Johnson, M.E., Meade, L.M. \& Underdown, D.R., 1995, 'Enterprise Engineering: A Discipline?', in Proceedings of the Society for Enterprise Engineering, Orlando, FL, June 1995, viewed 14 September 2012, from http:// webs.twsu.edu/enteng/ENTENG1.html.

Lincoln, Y.S. \& Guba, E.G., 1985, Naturalistic Inquiry, Sage Publications, Beverly Hills, CA.

Lowenstein, A., 2004, 'Gerontology coming of age: the transformation of social gerontology into a distinct academic discipline', Educational Gerontology 30 129-141. http://dx.doi.org/10.1080/03601270490266293
Luhmann, L., 1993, Risk: A Sociological Theory, Aldine de Gruyter, New York. http:// dx.doi.org/10.1515/9783110870343

Maynard, H.B., 1971, Industrial Engineering Handbook, 3rd edn., McGraw Hill, New York.

Mayring, P., 2000, 'Qualitative content analysis', Forum: Qualitative Social Research 1(2), viewed 05 May 2012, from http://217.160.35.246/fqs-texte/2-00/200mayring-e.pdf

McEntire, D.A., 2003, 'Searching for a Holistic Paradigm and Policy Guide: A Proposal for the Future of Emergency Management', International Journal of Emergency Management 1(3), 298-308. http://dx.doi.org/10.1504/IJEM.2003.003295

Miles, M. \& Huberman, A.M., 1994, Qualitative Data Analysis, Sage Publications, Thousand Oaks, CA.

Minichiello, V., Aroni, R., Timewell, E. \& Alexander, L., 1990, In-Depth Interviewing: Researching People, Longman Cheshire, Hong Kong.

Moed, H.F., 2005, Citation analysis in research evaluation, Springer, Dordrecht, Netherlands.

Moore, H., 1956, 'Towards a theory of disaster', American Sociological Review 21 734-737. http://dx.doi.org/10.2307/2088426

Nachmias, D. \& Nachmias, C., 1976, Research methods in the Social Sciences, St. Martin's Press, London.

Neuendorf, K.A., 2002, The Content Analysis Guidebook, Sage Publications, Thousand Oaks, CA.

Norwood, R.H., 1958, 'The Logic of Discovery', The Journal of Philosophy 55(25), 1073-1089. http://dx.doi.org/10.2307/2022541

Patton, M.Q., 2002, Qualitative Research and Evaluation Methods, Sage, Thousand Oaks, CA.

Perry, J.L. \& Kraemer, K.L., 1986, 'Research Methodology in the Public Administration Review, 1975-1984', Public Administration Review 46, 215-226. http://dx.doi. org/10.2307/3110436

Pierce, S.J., 1991, 'Subject areas, disciplines and the concept of authority', Library and Information Science Research 13, 21-35.

Popper, K.R., 1959, The Logic of Scientific Discovery, Hutchinson, London.

Popper, K.R., 1972, Objective Knowledge, Oxford University Press, Oxford.

Quarantelli, E.L., 1954, 'The Nature and Conditions of Panic', American Journal of Sociology 60, 267-275. http://dx.doi.org/10.1086/221536'

Reeves, T.C., Herrington, J. \& Oliver, R., 2005, 'Design Research: A Socially Responsible Approach to Instructional Technology Research in Higher Education', Journal of Computing in Higher Education 16(2), 97-116. http://dx.doi.org/10.1007/ BF02961476

Salvendy, G., 1982, Handbook of Industrial Engineering, John Wiley \& Sons, New York.

Schilling, J., 2006, 'On the pragmatics of qualitative assessment: Designing the process for content analysis', European Journal of Psychological Assessment 22(1), 28-37. http://dx.doi.org/10.1027/1015-5759.22.1.28

Smith, H.W., 1975, Strategies of Social Research: The Methodological Imagination, Prentice-Hall, Englewood Cliffs, N.J.

Snodgrass, A., 1987, An Archaeology of Greece: the present state and future scope of a discipline, University of California Press, Berkeley, CA.

South Africa (Republic), 1998, Green Paper on Disaster Management, Government Printer, Pretoria.

South Africa (Republic), 1999, White Paper on Disaster Management, Government Printer, Pretoria.

South Africa (Republic), 2002, Disaster Management Act 57 of 2002, Government Printer, Pretoria.

South Africa (Republic), 2011, National Development Plan Vision 2030, Nationa Planning Commission, The Presidency, Pretoria.

Steenbergen, M., Bos, R., Brinkkemper, S., Van de Weerd, I. \& Bekkers, W., 2010, 'The Design of Focus Area Maturity Models', in W.R. Winter, J.L. Zhao \& S. Aier (eds.), DESRIST 2010, LNCS 6105, pp. 317-332, Springer-Verlag, Heidelberg, Berlin.

Tesch, R., 1990, Qualitative Research: Analysis Types \& Software Tools, Falmer Press, Bristol, PA.

Tomic, T., 2010, 'The philosophy of information as an underlying and unifying theory of information science', Information Research 15(4), 714-728.

Van der Waldt, G., 2009, 'Public management and disaster risk reduction: potentia interdisciplinary contributions', Jàmbá 2(1), 14-27.

Van Niekerk, D., Mokonyama, T. \& Reid, P., 2002, 'Disasters: A Theoretical Perspective', unpublished study material, African Centre for Disaster Studies, North-West University.

Varley, A., 1994, Disasters, Development and Environment, John Wiley and Sons, New York.

Vermaak, N.J., 2004, 'Development interventions to disaster reduction', unpublished study material, African Centre for Disaster Studies, North-West University.

Weber, R.P., 1990, Basic Content Analysis, 2nd edn., Sage Publications, Newburry Park, CA.

Wisner, B., Gaillard, J.C. \& Kelman, I. (eds.), 2012, The Routledge Handbook of Hazards and Disaster Risk Reduction, Routledge, New York.

Ziman, J., 2000, Real Science. What it is, and what it means, Cambridge University Press, Cambridge. http://dx.doi.org/10.1017/CBO9780511541391 